\title{
TRANSFORMABLE CLASSROOM: DESIGNING AN ADAPTABLE CLASSROOM FOR STEM EDUCATION
}

\author{
Jimmy Tsz-Wai HO ${ }^{1 *}$, Thomas CHUNG ${ }^{2}$, Sau-Lai LEE ${ }^{3}$ \\ ${ }^{1} \mathrm{Mr}$, The Chinese University of Hong Kong, HONG KONG, twhosoa@gmail.com \\ ${ }^{2}$ Assoc. Prof., The Chinese University of Hong Kong, HONG KONG, tchung@cuhk.edu.hk \\ ${ }^{3} \mathrm{Dr}$, The Chinese University of Hong Kong, HONG KONG, venus@cuhk.edu.hk \\ ${ }^{*}$ Corresponding Author
}

\begin{abstract}
In recent years, STEM education has been introduced to equip students for the $21^{\text {st }}$-century working environment, one that requires problem-solving skills, innovation, design and creativity (Sen et al., 2018). Although the jury is still out on the exact definition of STEM education, it is clear that at least three pedagogical aspects are different from traditional mono-disciplinary subject learning, including learning content, attitudinal knowledge and instructional strategies. In STEM, learning content involves disciplinary knowledge, concepts and skills of science, technology, engineering and mathematics, attitudinal knowledge refers to positive attitudes and intellectual strengths such as creativity and mindset towards STEM learning, while instructional strategies embrace methods of applying and integrating disciplinary knowledge such as project and inquiry-based learning. It is argued that conventional classroom settings cannot facilitate such pedagogical needs of STEM due to the lack of adaptability.

This paper examines the spatial requirements of STEM education and demonstrates through an actual redesign project in a Hong Kong primary school how architectural design can support learning content, attitudinal knowledge and instructional strategies specific to STEM learning.
\end{abstract}

Keywords: Adaptability, STEM, instruction, primary school, architectural design

\section{INTRODUCTION}

STEM education has become one of the core subjects in the regular curriculum in many schools recently. It is believed that STEM education prepares students for 21st-century working requirements, as through STEM classes students will learn fundamental elements of research as well as skills in problem-solving, innovation, design and creativity (Sen et al., 2018). In Hong Kong, the Education Bureau has introduced STEM education to the local school curriculum since 2015.

Although STEM education is expanding rapidly globally, there is as yet no consensus on what STEM education is, what the objectives of STEM learning should be and how it should be taught (Kelley and Knowles, 2016). For example, scientists and educators continue to debate the nature of STEM. Is it a monodisciplinary, multidisciplinary, interdisciplinary or transdisciplinary subject? (English, 2016). While some suggest that the main goal of STEM education is to build up students' STEM literacy, which refers to the ability to identify and apply STEM contents to understand and solve problems that are otherwise impossible 
through monodisciplinary approaches (Washington STEM Study Group, 2011), others suggest that in STEM students are expected to consolidate conceptual, procedural, and attitudinal content with affective and procedural skills to solve real problems and fulfil individual personal goals (Zollman, 2012).

Regardless of whichever objectives are to be achieved, the three pedagogical aspects of learning content, attitudinal knowledge and instructional strategies for STEM are clearly different from those of traditional mono-disciplinary subjects (See Table 1). This paper will first describe the STEM characteristics of these three aspects, followed by highlighting various drawbacks of the conventional classroom setting to facilitate STEM learning. We will then use a built design case to illustrate how a classroom redesign using the principle of adaptability in architectural design can better support such elements of STEM education.

\section{STEM LEARNING}

\subsection{Learning Content for Stem}

Kelley and Knowles (2016) suggest that the key contents of STEM education cover four major areas: Engineering design, scientific inquiry, technological literacy, and mathematical thinking. Engineering design refers to the application of scientific knowledge and mathematical reasoning to problem-solving. Scientific inquiry refers to basic skills in research, to ask questions, make hypotheses, conduct investigations and draw conclusions. Technological literacy refers to the design, making and use of artifacts. Mathematical thinking refers to the skills to make abstractions, connections, create new ways to describe situations and make predictions. To support the acquisition of concepts and skills in these four areas, a wide variety of learning tools, multiple representations and some in-between translations media are needed. For example, to learn how to build a robot to walk a straight path, students may need multiple representations to learn the steps to assemble the parts. They may learn the installation steps by watching a video, check the materials that are missing from the instruction manual, and learn how to operate a screwdriver from the instructors.

Although multiple representations are also used in other subjects such as literature, Moore and his associates (2013) suggested that the use of multiple representations, including specific models, images, symbols and language and their translations between each other, are particularly beneficial in developing representations of the world and scientific concepts in an interdisciplinary manner.

Moreover, when students assemble a robot, they may need to use different tools such as a screwdriver, drill or cutter. Knowing how to use these different tools effectively is a key competence in STEM education (Barlex, 2007). These tools are not regular learning items in the classrooms, thus making STEM education different from other subjects. Finally, in-between devices are needed for STEM education. For example, before a student will try out the computational codes on a robot to control its movement, the student will usually try out the code in computer software. The computer is an in-between translational device that supports the students to test their ideas before it is implemented for view. This use of an in-between device is less common in other subjects.

\subsection{Attitudinal Knowledge of Stem}

In addition to the conceptual knowledge in different subject domains and practical skills in production and problem solving, Martín-Páez and his team (2019) suggest that STEM education also include the development of a positive attitude towards STEM and attitudinal knowledge that are important for success in STEM. Students hold different attitudes towards the different disciplines in STEM. For example, many students hold a negative attitude towards mathematics and that negativity grows with age (Utsumi and Mendes, 2000). At the same time many students hold a positive attitude towards technology (Rees and Noyes, 2007). They enjoy using technology even from a very young age. How teachers can help students develop a positive attitude to STEM and whether STEM teachers can use students' interest in one discipline to captivate their interest in another discipline has become an essential "quest".

As STEM education emphasizes application of knowledge to create a solution to solve real-life problems, research in STEM education (Boaler, 2016; León et al., 2015) emphasizes strategies to develop students' creativity, autonomy, their motivation to take academic risks, their capacity to cope with failures and their mindset to treat mistakes as part of learning. Kuhlthau and Maniotes (2010) call these competencies "knowhow-to-learn" knowledge.

\subsection{Instructional Strategies in Stem}

Several instructional strategies are often used in STEM education, including project-based learning that emphasizes the application of disciplinary knowledge, inquiry-based learning that emphasizes the integration 
of disciplines and use of real-world examples (Martin-Paez et al., 2019) and guided project-based inquiry learning that combines the strength of the two approaches (Chu et al., 2017). Common to these approaches is their dedication to create a student-centred classroom that encourage self-initiated active learning and critical thinking through investigation of real-life problems. Self-skills highlighted in these pedagogies encourage students to make self-initiated academic choices, regulate their own learning pace, monitor and evaluate their own progress towards their own goals (Trilling \& Fadel, 2009). Cooperative learning and peer learning are also underscored in these approaches. Students are encouraged to use their reasoning to review the available information critically. Teachers as the source and authority of knowledge are deemphasized (Gomez and Albrecht, 2014). The teacher becomes a facilitator in the classroom to support students to develop social and emotional skills to collaborate and provide constructive feedback to fellow classmates (Keiler, 2018).

Table 1. Three Aspects of STEM Learning

\begin{tabular}{|l|l|}
\hline & STEM learning \\
\hline \multirow{4}{*}{ Learning Content } & - Scientific Inquiry \\
& - Technological literacy \\
& - Engineering design \\
& - Mathematical thinking \\
\hline \multirow{3}{*}{ Attitudinal Knowledge } & - Develop positive attitude towards STEM \\
& - Develop intellectual strength: creativity, grit, and growth \\
& mindset \\
\hline Instructional strategies & - Project-based, inquiry-based \\
& - Student centered \\
& - Emphasize collaboration and group learning \\
& - Emphasize self-motivation, self-regulation and self-direction \\
& skills \\
\hline
\end{tabular}

STEM learning therefore comprises a multi-modal acquisition of learning content, a positive, transdisciplinary mindset of "know-how-to-learn" attitudinal knowledge and instructional strategies that favour student-centred, project-based inquiry while fostering an atmosphere for collaborative peer learning. What then needs to change in the physical setting of a conventional classroom to better support STEM education?

\section{SHORTFALLS OF A CONVENTIONAL CLASSROOM SETTING}

Figure 1 shows how a typical classroom is commonly organized in Hong Kong. At the front, a blackboard and a teaching console are used as the main stage for instruction. The blackboard is usually covered with notes of daily routines, assignment lists, administrative notice, and announcements. At the back, a big bulletin board is usually covered with decorations that are individualized for each class or subject-specific learning materials. The decorations and learning materials are usually renewed once every few months. On the two sides, there are usually windows on top with shelves at the bottom for holding stationery, homework and textbooks. In the middle, rows of study desks and chairs in pairs face the blackboard. This rigid arrangement of "set piece" components with fixed locations, predetermined functions and generic usages has numerous drawbacks. 


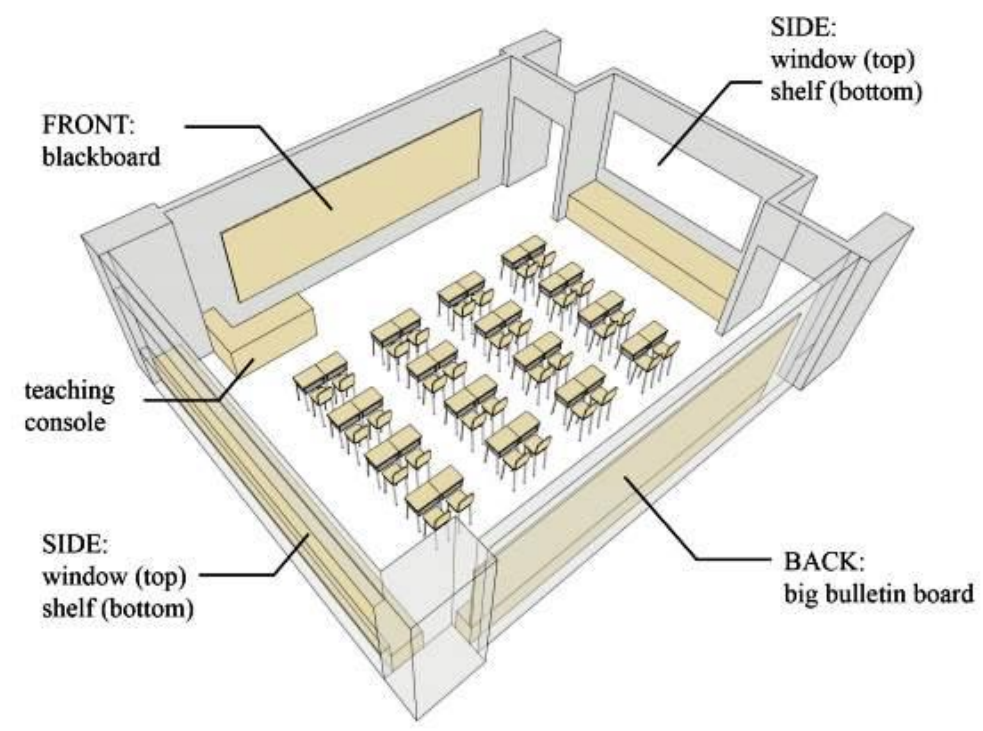

Fig. 1. Typical Classroom Configuration in Hong Kong Primary Schools

Regarding learning content, there is no designated space for the storage of tools that are commonly used in STEM classes. As students have to be trained to use some of these tools and some of the tools must be used under adult supervision, proper storage for the tools is needed. Also, although multiple portrayals such as blackboard and projector are available in a typical classroom, usually they cannot be used in parallel. The screen must be lifted when the blackboard is used. This hinders the simultaneous display of representation in different modalities. Finally, in-between devices such as computer or blackboard is available but generally inaccessible to students. Only the teacher can use those devices.

Regarding attitudinal knowledge, the blackboard and the teacher's console at the front of the classroom implies a teacher-centred hierarchy that almost prescribe a chalk-and-talk teaching mode. The teachercentred, unidirectional communication also limits the possibility of the students to make self-guided academic choices, regulate their own learning progress, and evaluate their own performance because the learning outcomes, the steps to achieve the outcomes, and the standards of success and failure are all set by the teacher.

Regarding instructional strategies, it is difficult to use problem or inquiry-based learning in the typical setting because rows of standardized student desks and chairs occupy most of the floor space, making grouping and discussion difficult. Typically, personal items such as school bags and lunch boxes further obstruct the in-between circulation space, making it harder for peer collaboration or the performance of motoric tasks (e.g. robotics) that demand floor space. In addition, given the limited size of the regular student desks and spare space in the classroom, there is no working area available for the creation and testing of designed prototypes.

With so many lacks, hindrances and constraints, a classroom redesign that can properly support STEM pedagogical needs is called for. Arguably, a STEM setting should be highly adaptable to facilitate learning content that covers a wide range of disciplines, learning modes and methods.

\section{BACKGROUND OF PROJECT SCHOOL (CASTAR)}

Po Leung Kuk Castar Primary School (CASTAR) in Hong Kong has a standard school design that dates from the 2000s. The name CASTAR itself represents the school's vision to promote Creativity, Acceptance, SelfConfidence, Talent, Achievement and Responsibility. In the government's 2015 policy address, local schools are encouraged to "strengthen STEM ability, nurture creativity, collaboration and problem-solving skills, foster innovation and entrepreneurial spirit needed in the 21st century" (Education Bureau, 2016, i). For CASTAR, STEM education has been embedded in the key learning areas (KLA) of Science, Technology and Mathematics Education curriculum since 2015, and STEM classes are conducted either in a regular classroom or in the computer lab when it is needed (Fig. 2). The computer lab originally had clusters of fixed computer consoles with five-to-six computers, desks and chairs in a group. As this configuration contained too many limitations, the school commissioned the authors to transform the computer lab into a space that would meet the pedagogical needs of STEM learning. 

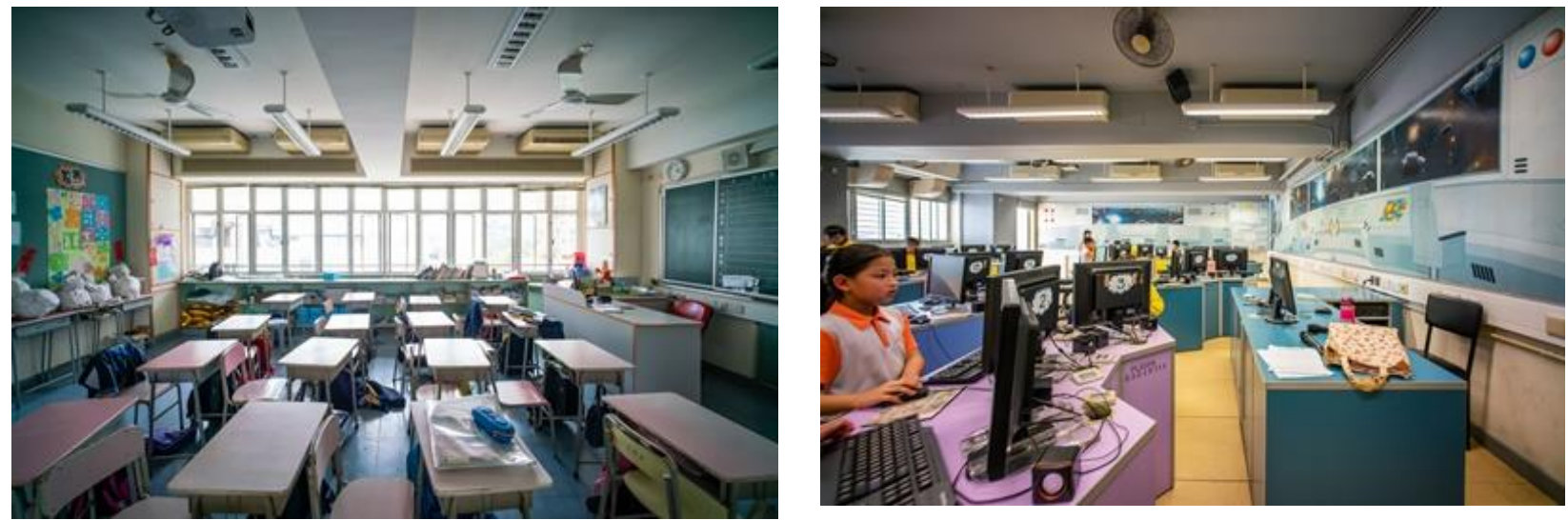

Fig. 2. Photos of Typical Classroom (Left) and Old Computer Lab (Right)

\section{DESIGNING FOR ADAPTABILITY}

Using the principle of adaptability in architectural design, CASTAR's computer lab has been substantially overhauled to become a new multipurpose classroom, a redesigned space that supports the various STEM requirements of different learning tasks, development of positive attitude and implementation of project/inquiry-based instructional strategies.

First, we redesigned the multipurpose classroom to support the serial or simultaneous presentation of media in different modalities. Second, we converted the organization of the fixed elements of the classroom to support student-centred, self-guided, self-regulated learning. Third, we introduced new mobile furniture as individualised workstations that can adopt flexible configurations and combinations to better accommodate different learning tasks and instructional strategies. (Fig. 3 shows the new design)

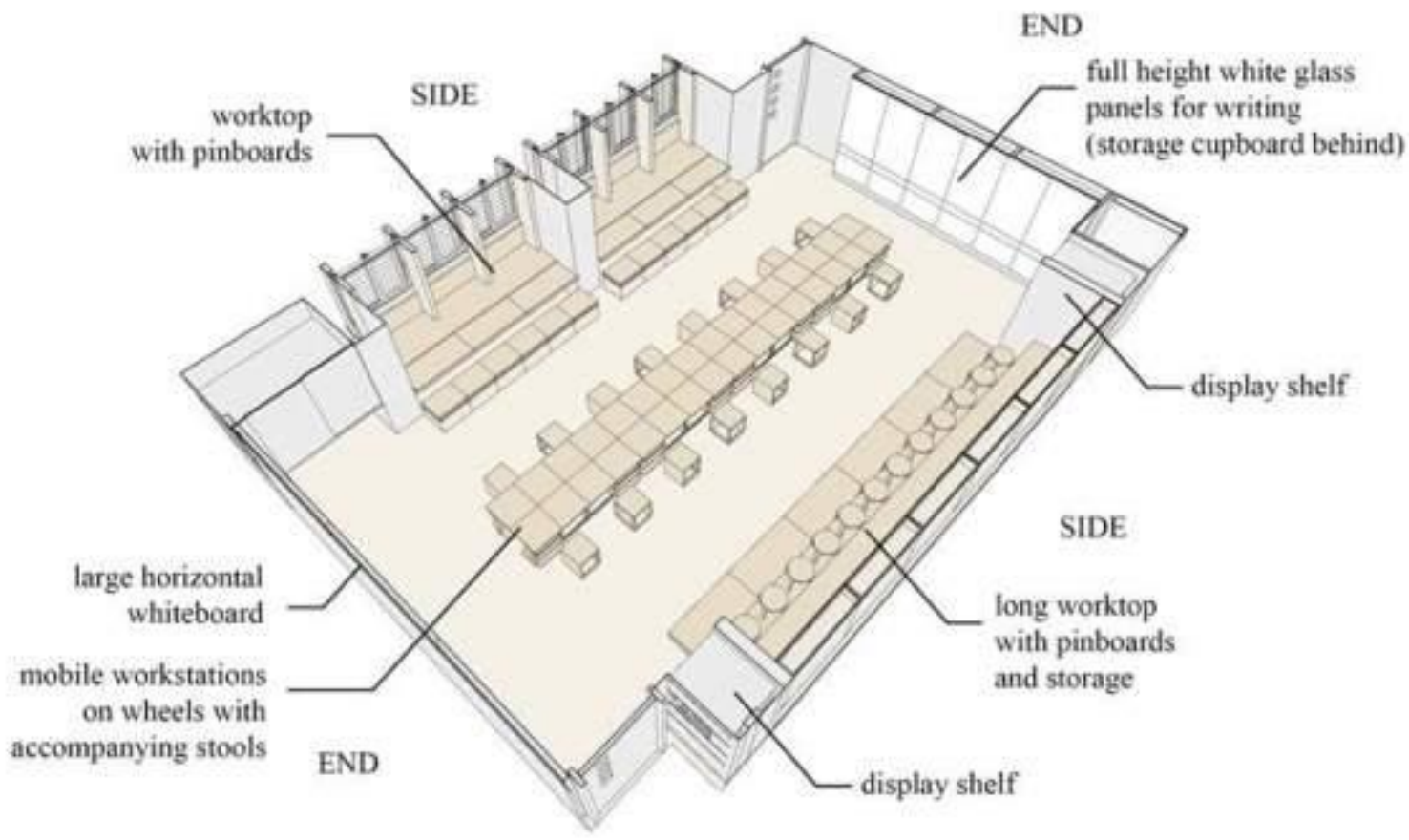

Fig. 3. New Design of Multipurpose Classroom for STEM

\subsection{Support for the Use of Multiple Representations}

The elevations of the classroom are organized to maximize areas for instruction and discussion. On one end wall, a long horizontal whiteboard is provided for writing and drawing on as well as projection (Fig. 6). On the other end, full-height white glass panels are installed also for sketching and writing on (Fig. 7). Along the two 
long side elevations, arrays of pinboards with small divisions are provided for pinning up instructional guides when needed.

Such multiple elevations enable the simultaneous display of learning materials using different media. It also supports parallel displays of instructions for different stages of a learning task so that learners will be able to plan ahead - consider what they need to complete and how much time they have for each task on their own terms. For example, teachers may sketch and explain the mechanism of a simple robotic arm on a whiteboard, and project images of the mechanical parts adjacent to the hand drawing. Students then follow the printed instructions of the sequential steps of assembling the robotic arm placed on pinboards and try assembling their own. For those who want to understand the structure of the robotic arm threedimensionally, they can also refer to a pre-assembled demonstration placed on a visible display shelf. Students also have access to iPads as in-between devices for their own use, and the iPads are stored behind the glass wall panels.

\subsection{Support for Development of Positive Attitudinal Knowledge}

Spatial dimensions are customized to be child-friendly and there is no dedicated console or furniture for the teacher. This aims at undirecting the authority of the teacher in the classroom. In fact, there is not a single "front" of the classroom but multi-faceted interior facades that present a diversity of learning scenarios that happen all around the students. Students are encouraged to direct their own learning within this multifunctional interior landscape.

A large amount of space is prepared for storage and organization of STEM resources, including working tools, mechanical parts and large equipment. When resources are organized and properly labelled, students would be able to retrieve the resources on their own when they need them. They would not need to wait and rely on the teachers to direct them on what to do and how to complete a task. Students are then reassured and encouraged to creatively use the available resources to complete the tasks at hand, or start with imaginatively exploring ones that captivate their initial interest.

Various desktop surfaces are provided to anticipate student needs and preferences in carrying out their learning tasks in STEM. An unobstructed long workbench below the pinboards allows intensive or individual hands-on tasks in close proximity to the pinned-up instructions as well as access to power sockets nearby. The mobile workstations provide additional working space for group exploration or group work. Students can choose the working space according to the task nature or their personal preference to work individually, in pairs or in a group. This further supports the students to make choices to optimize their learning environment and to direct their own learning at their own pace.

\subsection{Support for Diverse Learning Strategies}

To accommodate various learning scenarios, we designed workstations on wheels that are flexible, practical and multifunctional. At 60 cubic centimetres each, twelve mobile workstations have been constructed (Fig. 4). Each of these workstations can be easily moved and grouped to fit grouping and zoning needs (Swagerty and Hodge, 2019). For example, the workstations can be combined to form islands for group discussion, an O-shaped round table, or they can be collapsed to free up floor space or parked under the whiteboard for demonstrations and creative works in small groups.
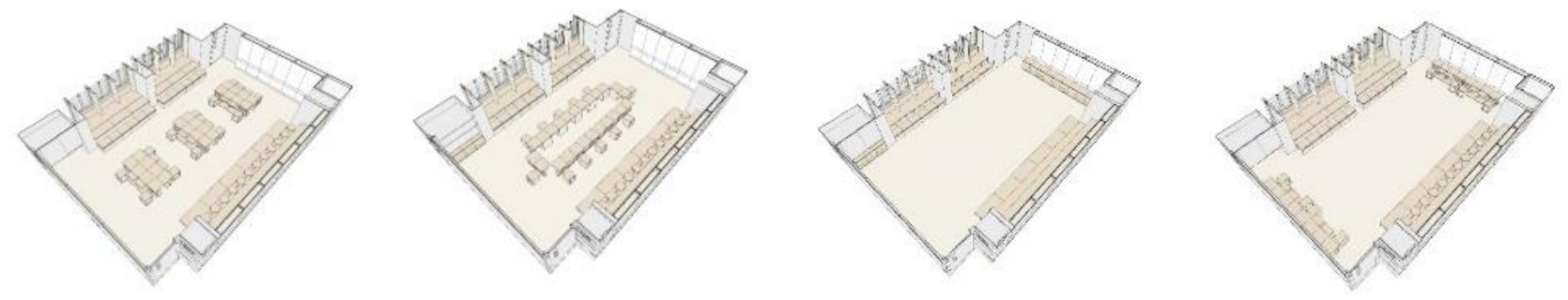

Fig. 4. Flexible Configurations of New Classroom

Knowing that learning activities in STEM can be very diverse and require lots of tools and materials, we designed panels of the workstation to be openable in order to provide extra working surfaces for sketching ideas and group discussion. There are multiple small compartments for organized storage of tools, components and materials. The workstation also houses a small wooden box that can be used as an extra table, storage space or a stool for sitting. Such flexible multiple configurations allow teachers and students to 
make adaptations themselves according to their instructional and learning needs.

The mobile workstation also supports the optimization of different floor usage (Fig. 5 and Fig. 8). Even when all workstations are expanded, the circulation space remains unobstructed. The teacher can easily move close to and be among the students to provide feedback to individuals or groups, demonstrate procedures and coach students how to perform certain procedures. Students can also exchange ideas and share resources with fellow classmates as well as ask questions and seek help from them easily. As the responsibility of knowledge provision and problem-solving becomes decentralized from the teacher to peer learning and interaction, a more collaborative and cooperative atmosphere, rather than negative competition, should gradually be shaped.

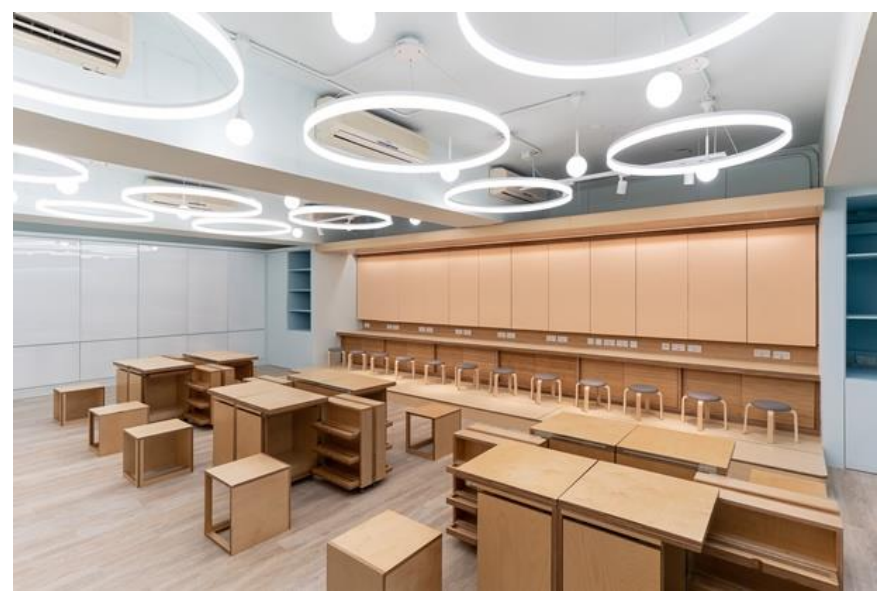

Fig. 5. Mobile workstations for multiple configurations

\section{DISCUSSION}

Using CASTAR's multipurpose STEM room redesign as a case example, this paper demonstrates how the principle of adaptability in architectural design can be used to address pedagogical needs in STEM education. However, there are several points to be noted in this design.

Although an organized space may encourage autonomy and self-determination in learning, more effort is needed in lesson planning to maximize the utility of the space. Teachers should be given time to adapt to the new setting in order to develop new pedagogies. Students will also need to familiarise themselves with the mobile workstations and be trained to operate them safely or be able to manoeuvre them to create the configurations that they want. Training sessions will be needed to teach students to use the workstations properly before they can start to use them in creative ways. As STEM education emphasizes applying interdisciplinary knowledge to solve real-world problems, the usage of the new multipurpose room can also go beyond in-class practice. Extracurricular activities could be scheduled to explore questions outside the standard curriculum. Post-occupancy review of spatial usage with school stakeholders would need to be conducted iteratively to maximize the performance of new design continuously (Higgins et al., 2005). Finally, common to most adaptable furniture that enables frequent operations, a budget should be allowed for maintenance due to wear and tear.

\section{CONCLUSION}

As STEM education continues to develop, spatial design could be more aligned to support its specific instructional strategies and attitudinal knowledge and learning content. This paper demonstrated how a paradigm of adaptability can support STEM learning through redesigning a multipurpose room. Further research on adaptable designs beyond multipurpose classrooms would be beneficial to the promotion of whole-school development of STEM.

\section{ACKNOWLEDGEMENT}

This research is partially supported financially under the Place-making item of the Jockey Club Positive Education "Ascend and Radiate" (JC-PEAR) project by the Hong Kong Jockey Club and the Faculty of Social Science of The Chinese University of Hong Kong. We would also like to acknowledge Po Leung Kuk Castar Primary School for their active participation in this research. 


\section{APPENDIX}

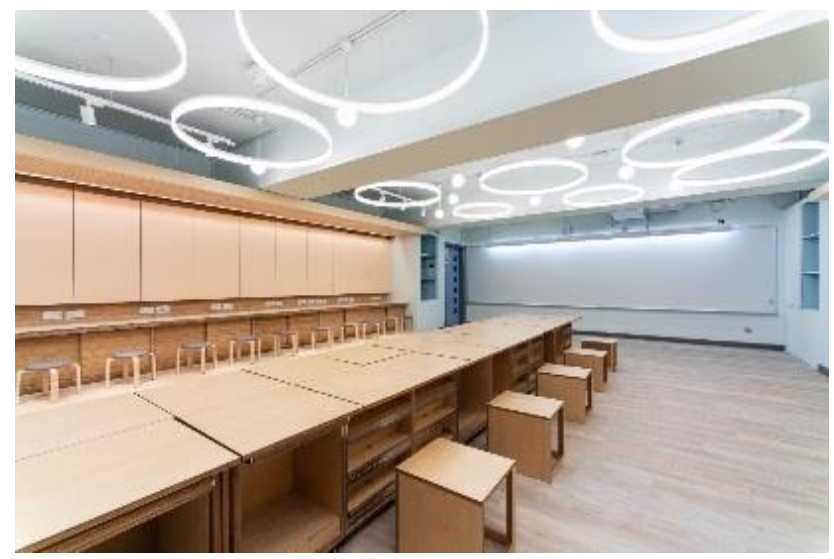

Fig. 6. New Design: Long Horizontal Whiteboard At The End

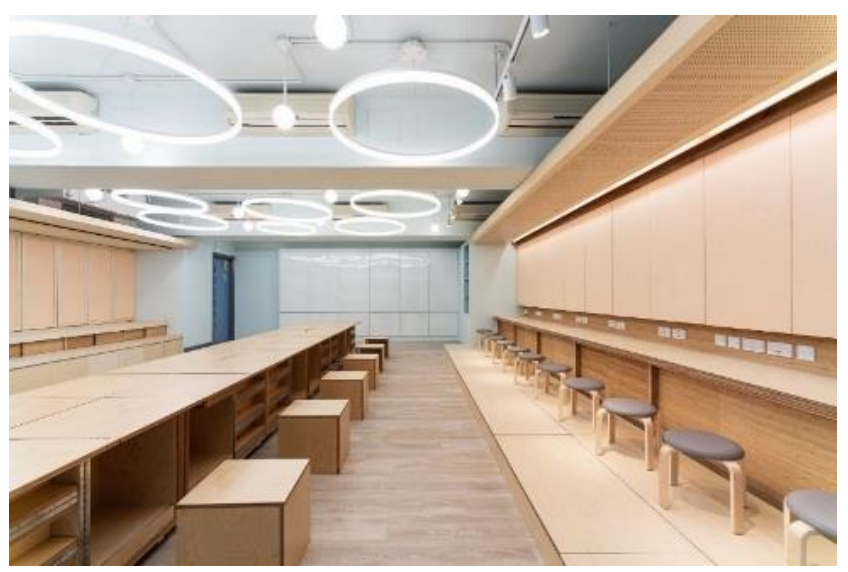

Fig. 7. New Design: Long Worktop At Side; Full Height White Glass Panels At The End

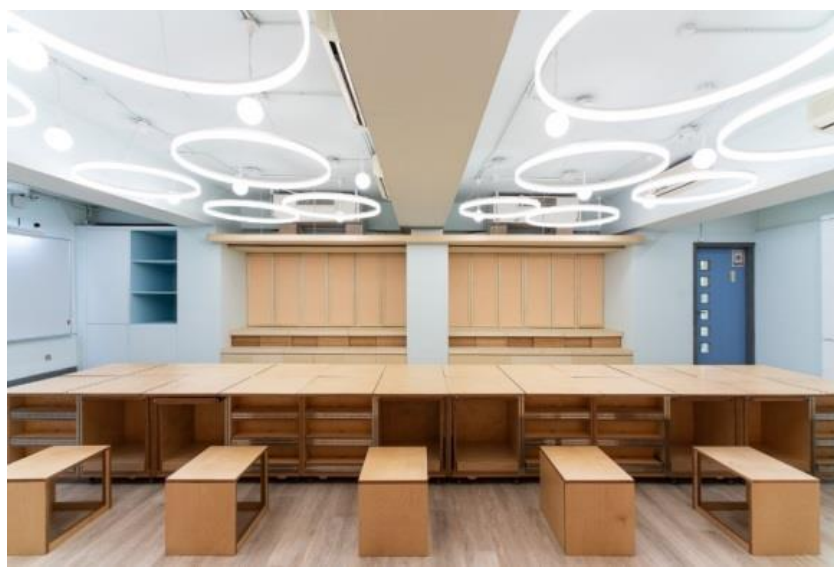

Fig. 8. New Design: Worktop At Window Side; Mobile Workstations Expanded In The Front

\section{REFERENCE LIST}

Barlex, D. (2007). Capitalising on the Utility Embedded in Design and Technology Activity: An exploration of cross-curricular links. The Design and Technology Association International Research Conference 2007. University of Wolverhampton, Telford Campus, 4,5,6 July. Wellesbourne: The Design and Technology Association, pp. 5-10 
Proceedings of SOCIOINT 2020-7th International Conference on Education and Education of Social Sciences,

Beth Murphy. (2019, October 16). What STEM Mindset Is ... and Why Everyone Should Have One. Connected Science Learning. Retrieved from http://csl.nsta.org/2019/10/what-stem-mindset-is-andwhy-everyone-should-have-one/

Boaler, J. (2016). Mathematical mindsets: Unleashing students' potential through creative math, inspiring messages, and innovative teaching. Jossey-Bass.

Boonprasert, L., Tupsai, J., \& Yuenyong, C. (2018). Grade 8 students' capability of analytical thinking and attitude toward science through teaching and learning about soil and its' pollution based on science technology and society (STS) approach. AIP Conference Proceedings, 1923(1), 030070. https://doi.org/10/ggwzz9

Brown, J. (2012). The Current Status of STEM Education Research. 13(5), 7-11.

Chu, S. K. W., Reynolds, R. B., Tavares, N. J., Notari, M., \& Lee, C. W. Y. (2017). 21st Century Skills Development Through Inquiry-Based Learning: From Theory to Practice (pp. 136). Springer Singapore. https://doi.org/10.1007/978-981-10-2481-8

Cuoco, A., Paul Goldenberg, E., \& Mark, J. (1996). Habits of mind: An organizing principle for mathematics curricula. The Journal of Mathematical Behavior, 15(4), 375-402. https://doi.org/10/cgpran

Education Bureau of Hong Kong Special Administrative Region Government. (n.d.). STEM Education. Retrieved from https://stem.edb.hkedcity.net/en/home/

Education Bureau of Hong Kong Special Administrative Region Government. (2016a). Learning and Teaching Resources for STEM Education. Retrieved from https://stem.edb.hkedcity.net/wpcontent/uploads/2016/06/Learning-and-Teaching-Resources-for-STEM-Education-ENG.pdf

Education Bureau of Hong Kong Special Administrative Region Government. (2016b). Report on Promotion of STEM Education: Unleashing Potential in Innovation. Retrieved from https://www.edb.gov.hk/attachment/en/curriculumdevelopment/renewal/STEM\%20Education\%20Report Eng.pdf

English, L. D. (2016). STEM education K-12: Perspectives on integration. International Journal of STEM Education, 3(1), 3. https://doi.org/10.1186/s40594-016-0036-1

Gomez, A., \& Albrecht, B. (2014). True Stem Education. Technology and Engineering Teacher, 73(4), 8-16.

Higgins, S., Hall, E., Wall, K., Woolner, P., \& McCaughey, C. (2005). The Impact of School Environments: A literature review (p. 47). Design Council. https://eprint.ncl.ac.uk/12574

John Kyere. (2016). The Effectiveness of Hands-on Pedagogy in STEM Education [Unpublished doctoral dissertation, Walden University]. Retrieved from https://ddc-elib-comtw.easyaccess2.lib.cuhk.edu.hk/doc/10239707

Keiler, L. S. (2018). Teachers' roles and identities in student-centered classrooms. International Journal of STEM Education, 5(1), 34. https://doi.org/10/ggwz4n

Kelley, T. R., \& Knowles, J. G. (2016). A conceptual framework for integrated STEM education. International Journal of STEM Education, 3(1), 11. https://doi.org/10.1186/s40594-016-0046-z

Kuhlthau, C. C., \& Maniotes, L. K. (2010). Building Guided Inquiry Teams for 21st-Century Learners. School Library Monthly, 26(5), 18-21.

Lansiquot, R. D., \& SpringerLink. (2016). Interdisciplinary Pedagogy for STEM: A Collaborative Case Study. Palgrave Macmillan US : Imprint: Palgrave Macmillan.

León, J., Núñez, J. L., \& Liew, J. (2015). Self-determination and STEM education: Effects of autonomy, motivation, and self-regulated learning on high school math achievement. Learning and Individual Differences, 43, 156-163. http://dx.doi.org/10.1016/j.lindif.2015.08.017

Li, Y., Wang, K., Xiao, Y., \& Froyd, J. E. (2020). Research and trends in STEM education: A systematic review of journal publications. International Journal of STEM Education, 7(1), 1-16. https://doi.org/10.1186/s40594-020-00207-6

Martín-Páez, T., Aguilera, D., Perales-Palacios, F. J., \& Vílchez-González, J. M. (2019). What are we talking about when we talk about STEM education? A review of literature. Science Education, 103(4), 799822. https://doi.org/10/ggtc4h 
Moore, T. J., Miller, R. L., Lesh, R. A., Stohlmann, M. S., \& Kim, Y. R. (2013). Modeling in Engineering: The Role of Representational Fluency in Students' Conceptual Understanding. Journal of Engineering Education, 102(1), 141-178. https://doi.org/10/f4vmar

Rees, H., \& Noyes, J. M. (2007). Mobile telephones, computers, and the internet: Sex differences in adolescents' use and attitudes. Cyberpsychology \& Behavior: The Impact of the Internet, Multimedia and Virtual Reality on Behavior and Society, 10(3), 482-484. https://doi.org/10.1089/cpb.2006.9927

Sen, C., Ay, Z. S., \& Kiray, S. A. (2018). STEM Skills in the 21st Century Education. In Research Highlights in STEM Education (p. 81). ISRES Publishing.

Sengupta, P., Shanahan, M.-C., \& Kim, B. (2019). Critical, Transdisciplinary and Embodied Approaches in STEM Education (1st ed. 2019). Springer International Publishing : Imprint: Springer.

Swagerty, L. M., \& Hodge, T. (2019). Fostering Creativity and Curiosity: Developing Safer Elementary STEM Learning Spaces. Technology and Engineering Teacher, 78(8), 20-23.

Trilling, B. (2009). 21st century skills: Learning for life in our times (1st ed). Jossey-Bass.

Tseng, K.-H., Chang, C.-C., Lou, S.-J., \& Chen, W.-P. (2013). Attitudes towards science, technology, engineering and mathematics (STEM) in a project-based learning (PjBL) environment. International Journal of Technology and Design Education, 23(1), 87-102. https://doi.org/10/cri2nr

Utsumi, M. C., \& Mendes, C. R. (2000). Researching the Attitudes Towards Mathematics in Basic Education. Educational Psychology, 20(2), 237-243. https://doi.org/10/dpw5rx

Wendt, J. L., \& Apugo, D. L. (2019). K-12 STEM education in urban learning environments. IGI Global.

Wu, S. P. W., \& Rau, M. A. (2019). How Students Learn Content in Science, Technology, Engineering, and Mathematics (STEM) Through Drawing Activities. Educational Psychology Review, 31(1), 87-120. https://doi.org/10/ggtfcr

Xie, Y., Fang, M., \& Shauman, K. (2015). STEM Education. Annual Review of Sociology, 41(1), 331-357. https://doi.org/10/gf66mz

Zollman, A. (2012). Learning for STEM Literacy: STEM Literacy for Learning: STEM Literacy for Learning. School Science and Mathematics, 112(1), 12-19. https://doi.org/10/fxsfpz 